\title{
Age discrimination in the workplace hurts us all
}

\author{
When older workers are discriminated against, everyone is affected. Age discrimination negatively \\ impacts not only individual workers but also their families and the broader economy, argues Joo \\ Yeoun Suh.
}

A s COVID-19 spreads throughout the United States and the rest of the world, the resulting disruptions to the economy mean that it is highly likely the incidence of age discrimination will increase. This may include employers laying off older staff members or not considering older candidates when rehiring. This short-term thinking ignores longterm consequences that will affect people of all ages.

Age discrimination takes an enormous toll on individual workers and their families, but it also has a substantial impact on the economy. According to the AARP's recent report 'The Economic Impact of Age Discrimination', bias against older workers cost the US economy an estimated US $\$ 850$ billion in gross domestic product (GDP), 8.6 million jobs and US $\$ 545$ billion in lost wages and salaries in 2018 alone.

Meanwhile, previous experience points to an impending surge in age discrimination issues stemming from the current economic downturn. During the 2007-2009 Great Recession, age discrimination complaints related to hiring and firing increased by $3.4 \%$ and $1.4 \%$, respectively, in concert with each percentage point increase in monthly unemployment rates. Unfortunately, the contraction the economy is undergoing as a result of the COVID-19 pandemic is even worse than that of the Great Recession.

Many older people believe that their age is a disadvantage when looking for a job. Evidence suggests that older job applicants get fewer callbacks than their younger counterparts with comparable resumes, contributing to extended periods of unemployment for many 50-plus jobseekers. This is especially true for women and minoritized racial groups, as incidents of age discrimination in the workplace often intersect with gender and racial discrimination. The reality is that those most likely to be affected by age discrimination are those least able to afford it. Lower-income workers may have fewer options to switch jobs, and historically disadvantaged racial and ethnic groups are more likely than others to feel trapped in their present role.
For months now, we have been seeing the impact of the pandemic on employment, with record-breaking numbers of unemployment claims filed in April and May of 2020 in the US. It is highly likely that age discrimination will persist after the pandemic if employers do not take steps to address it. To counteract these trends, federal and state anti-age discrimination laws must be vigorously enforced. Beyond that, we need to make changes in the way workplaces operate changes that will help in the near term but will signal a permanent shift as well. Companies should implement robust practices that promote age-diverse work environments, and their workers of all ages should be provided the apprenticeship opportunities they need to thrive in the workplace as they age.

Access to job-protected paid sick leave or paid family leave will help older workers stay employed during the current health and economic crisis. Some states have temporarily broadened access to paid sick leave in response to the virus, and several major companies have taken action to provide their employees with paid sick leave to allow those who feel ill to stay home. Paid family leave is also important if a family member tests positive for COVID-19, potentially creating a need for quarantine and family caregiving.

Employers should consider how to make workplaces truly embrace age diversity and inclusion. They would be wise to do so, even from a business perspective. There are strong economic benefits for businesses to make such changes, including that an age-diverse workforce gives companies more insight into age-diverse marketplaces. AARP's initiative, 'Living, Learning and Earning Longer', a collaboration with the Organization for Economic Co-operation and Development (OECD) and the World Economic Forum (WEF), advances the business case for age diversity and highlights promising practices from around the world. Efforts to cultivate multigenerational workforces, which span technology training and sharing career experiences and skills, have clear value for employers and employees alike.

If we are to benefit from the value that older workers bring to the workforce, businesses will need to make a serious commitment to concepts like the multigenerational workforce. Global executives are beginning to recognize that multigenerational workforces are key to business growth and success. However, more than half of global companies still do not include age in their company's diversity and inclusion policy. Clearly more needs to be done to align systems to better respond to the demographics at large. Efforts to do so are necessary to create inclusive workplaces that take active steps to enable employees to realize their full and unique potential.

Company-sponsored programs that promote age diversity and inclusion in tangible ways would have encouraged 60\% of those aged 50-plus who retired because of age discrimination to remain in the workforce longer. There is a compelling case for increasing age inclusion in the workforce beyond meeting legal mandates such as the Age Discrimination in Employment Act of 1967. People are living longer and either want or need to continue working. Providing these people with access to incomes ultimately creates a population with the resources to continue consuming and generating impact on the economy. But perceptions that prevent the hiring and advancement of older workers need to shift in order for these benefits to be captured.

This is an astoundingly difficult time for employees and employers alike. As we fight against COVID-19, we must not lose sight of older workers. With the skills and knowledge they've acquired over a lifetime, they can make enormous contributions to the work of pushing national and global economies toward recovery.

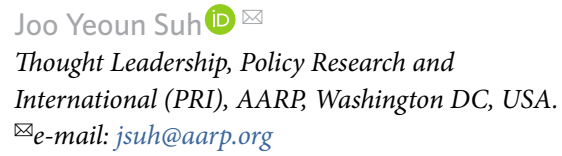

Published online: 11 February 2021 https://doi.org/10.1038/s43587-020-00023-1

Competing interests

The author declares no competing interests. 